\title{
Controle químico da mela-das-sementes e do carvão em cultivares de Brachiaria brizantha
}

\author{
Celso Dornelas Fernandes ${ }^{1}$, Jaqueline Rosemeire Verzignassi ${ }^{1}$, Guilherme Mallmann ${ }^{1}$, Carolina de Arruda Queiróz ${ }^{1}$
}

${ }^{1}$ Embrapa Gado de Corte, Av. Rádio Maia, 830, Zona Rural, CEP 79106-550, Campo Grande, Mato Grosso do Sul, Brasil. Autor para correspondência: Jaqueline Rosemeire Verzignassi (jaqueline.verzignassi@embrapa.br).

Data de chegada: 19/06/2015. Aceito para publicação em: 19/01/2016.

$10.1590 / 0100-5405 / 2102$

\section{RESUMO}

Fernandes, C.D.; Verzignassi, J.R.; Mallmann, G.; Queiróz, C.A.. Controle químico da mela-das-sementes e do carvão em cultivares de Brachiaria brizantha. Summa Phytopathologica, v.43, n.2, p.136-144, 2017.

O Brasil é o maior produtor, consumidor e exportador mundial de sementes de espécies forrageiras tropicais. Contudo, a produção tem sido ameaçada pela presença de fungos e fitonematoides, os quais podem reduzir a produtividade e/ou a qualidade das sementes produzidas, além de constituírem barreiras sanitárias para vários países importadores dessas sementes. Em Brachiaria spp., as principais doenças são a mela-das-sementes e o carvão, causadas, respectivamente, pelos fungos Claviceps maximensis e Ustilago operta. Apesar da grande demanda pelo setor produtivo, poucos são os estudos relacionados a estratégias de controle das doenças. Assim, realizou-se este trabalho objetivandose avaliar a eficiência de fungicidas no controle das referidas doenças. Implantaram-se quatro experimentos, sendo dois na Embrapa Gado de Corte, em Campo Grande-MS, e dois em Paraíso das Águas-MS. Foram utilizadas as cultivares BRS Piatã e Xaraés, ambas pertencentes à Brachiaria brizantha. Foram avaliados os efeitos de vários fungicidas ( $\mathrm{g}$ ia/ha), os quais foram aplicados em três épocas para Campo Grande: plantas com 10\% de antese, 20 e 40 dias após a primeira aplicação. Em Paraíso das Águas, os fungicidas foram aplicados uma única vez, nas plantas com $10 \%$ de antese. Na cultivar BRS Piatã, para Campo Grande, os melhores resultados obtidos para o controle da mela-dassementes foram com os tratamentos T7 (trifloxistrobina + ciproconazole $(150,0+$ $64,0)$ ) e T11 (primeira aplicação: piraclostrobina $(97,5)+$ epoxiconazole $(60,0)$, segunda aplicação: tebuconazole $(120,0)$, terceira aplicação: piraclostrobina
$(97,5)$ + epoxiconazole $(60,0))$. Na cultivar Xaraés, a doença foi menos expressiva nos tratamentos T4 (piraclostrobina $(175,0)$ ), T6 (azoxistrobina + ciproconazole $(80,0+32,0))$, T9 (primeira aplicação: piraclostrobina $(175,0)$; segunda e terceira aplicações: piraclostrobina + epoxiconazole $(99,75+37,5))$ e T11 (primeira aplicação: piraclostrobina $(97,5)+$ epoxiconazole $(60,0)$, segunda aplicação: tebuconazole $(120,0)$, terceira aplicação: piraclostrobina + epoxiconazole $(97,5+60,0))$. Não houve ocorrência de carvão para ambas as cultivares em Campo Grande. Para BRS Piatã, no experimento de Paraíso das Águas-MS, apesar da intensidade de mela-das-sementes e de carvão não terem sido expressivas, no tratamento T4 (piraclostrobina $(175,0)$ a produtividade de sementes puras foi $69,6 \%$ maior que a testemunha, produzindo $456,78 \mathrm{~kg}$ / ha, demonstrando alta relação benefício/custo com o referido tratamento. Tal resultado em T4 pode ter sido expressão de efeitos fisiológicos proporcionados pela piraclostrobina. A aplicação de fungicidas na parte aérea das plantas de BRS Xaraés de Brachiaria brizantha em Campo Grande, onde houve alta incidência dos fungos Alternaria spp., Bipolaris spp., Curvularia spp., Fusarium spp. e Phoma spp. nas sementes, revelou o efeito benéfico do tratamento, sobretudo do T7 (trifloxistrobina + ciproconazole $(150,0+64,0)$ ), o qual reduziu significativamente a ocorrência de Bipolaris spp., Fusarium spp. e Phoma spp. Em Paraíso das Águas, onde a incidência dos referidos patógenos foi menor, os resultados não foram conclusivos.

Palavras-chave: forrageiras, doenças, controle químico, efeito fisiológico.

\section{ABSTRACT}

Fernandes, C.D.; Verzignassi, J.R.; Mallmann, G.; Queiróz, C.A..Chemical control of smut and seed honeydew in cultivars of Brachiaria brizantha. Summa Phytopathologica, v.43, n.2, p.136-144, 2017.

Brazil is the world's largest producer, consumer and exporter of seeds of tropical forage species. However, production has been threatened by the presence of fungi and phytonematodes, which may reduce the productivity and / or the quality of produced seeds, besides constituting sanitary barriers for several countries that import these seeds. Considering Brachiaria spp., the main diseases are honeydew and smut in the seeds, caused by the fungi Claviceps maximensis and Ustilago operta, respectively. Despite the great demand by the productive sector, there are few studies related to control strategies for these diseases. Thus, this study was carried out with the aim of evaluating fungicide efficiency in the control of these diseases. Four experiments were implemented, two of them in Embrapa Gado de Corte, in Campo Grande-MS, and two in Paraíso das ÁguasMS. The cultivars BRS Piatã and Xaraés, both belonging to Brachiaria brizantha, were used. The effects of several fungicides ( $\mathrm{g}$ ai / ha) were evaluated; they were applied in three periods for Campo Grande: plants with $10 \%$ anthesis, 20 and 40 days after the first application. In Paraíso das Águas, fungicides were applied only once, in plants with $10 \%$ anthesis. For the cultivar BRS Piatã, in Campo Grande, the best results for honeydew control were obtained with treatments $\mathrm{T} 7$ (trifloxystrobin + cyproconazole $(150.0+64.0)$ ) and T11 (first application: pyraclostrobin (97.5) + epoxiconazole (60.0), second application: tebuconazole (120.0), third application: pyraclostrobin (97.5) + epoxiconazole (60.0)). For the cultivar BRS Xaraés, the disease was less expressive with treatments T4 (pyraclostrobin (175.0)), T6 (azoxystrobin + cyproconazole $(80.0+32.0)$ ), T9 (first application: pyraclostrobin (175.0), second and third application: pyraclostrobin + epoxiconazole $(99.75+37.5))$ and T11 (first application: pyraclostrobin (97.5) + epoxiconazole (60.0), second application: tebuconazole (120.0), third application: pyraclostrobin + epoxiconazole $(97.5+60.0))$. There was no occurrence of smut for both cultivars in Campo Grande. For BRS Piatã, in the experiment at Paraíso das Águas-MS, although the intensity of honeydew and smut was not significant, with treatment T4 (pyraclostrobin (175.0)), the yield of pure seeds was $69.6 \%$ higher than that of control, producing 456.78 $\mathrm{kg} / \mathrm{ha}$, which demonstrates a high benefit/cost ratio using this treatment. This result with T4 may have been the expression of physiological effects caused by pyraclostrobin. Fungicide application on the aerial part of Brachiaria brizantha plants cv BRS Xaraés in Campo Grande, where there was high incidence of the fungi Alternaria spp., Bipolaris spp., Curvularia spp., Fusarium spp. and Phoma spp. in the seeds, showed the beneficial effect of the treatment, especially $\mathrm{T} 7$ (trifloxystrobin + cyproconazole $(150.0+64.0)$ ), which significantly reduced the occurrence of Bipolaris spp., Fusarium spp. and Phoma spp. In Paraíso das Águas, where the incidence of these pathogens was lower, results were not conclusive.

Keywords: forage, diseases, chemical control, physiological effect 
O Brasil é considerado o maior produtor, consumidor e exportador mundial de sementes de espécies forrageiras tropicais $(7,11)$. Contudo, a sustentabilidade do sistema de produção de sementes se encontra ameaçada pela presença de patógenos associados, sobretudo fungos e nematoides, os quais podem reduzir a produtividade e/ou qualidade física e fisiológica, além de constituírem barreiras sanitárias para vários países importadores destas sementes.

A maior parte das sementes de espécies forrageiras comercializadas nos mercados interno e externo pertence ao gênero Brachiaria $(11,19)$ e as principais doenças incidentes no sistema reprodutivo de cultivares desta forrageira são a mela-das-sementes e o carvão, causadas, respectivamente, pelos fungos Claviceps maximensis e Ustilago operta (13).

O primeiro registro da mela-das-sementes de Brachiaria spp. foi feito por Fernandes et al. (5), em pastagem em Mato Grosso do Sul. A doença também foi relatada em sementes de Brachiaria decumbens no Rio de Janeiro (1) e em Minas Gerais (17). Atualmente, é possível que a mela-das-sementes de braquiária se encontre amplamente distribuída no Brasil, devido, especialmente, à inexistência de exigências normativas no que tange aos padrões de qualidade sanitária para as sementes de forrageiras destinadas ao comércio interno (7).

Baseado em caracteres morfológicos e gama de hospedeiro, o agente etiológico da mela-das-sementes de braquiária foi inicialmente descrito como Claviceps sulcata Langdon, forma perfeita de Sphacelia spp. (5). Contudo, análises de sequências de rDNA dos isolados brasileiros patogênicos à Brachiaria brizantha demonstraram alta similaridade com as sequências de $C$. maximensis Theis (14). Estudos moleculares recentes confirmaram a interação de $C$. maximensis e espécies de Brachiaria no Brasil (2).

Os sinais da doença caracterizam-se pela exsudação de gotas de coloração áurea referidas como mela ou honeydew (6). No início, o exsudato é pegajoso e atrativo a insetos. Posteriormente, torna-se mais consistente, podendo envolver toda a panícula e formar escleródios. A mela-das-sementes de Brachiaria spp. manifesta-se sob condições de alta umidade e baixas temperaturas associadas às frentes frias durante os estádios de florescimento e de maturação das sementes (21).

Reduções expressivas da produtividade e da qualidade das sementes de Brachiaria spp. têm sido observadas em campos com elevada intensidade de mela e carvão $(6,11)$. No caso da mela-dassementes, além das perdas diretas, é possível que alcaloides produzidos pelo fungo provoquem intoxicação em animais, quando estes se alimentam de grãos ou pastos contaminados (6). Também, tais doenças prejudicam o mercado de exportação do insumo, uma vez que esses agentes etiológicos constituem barreiras sanitárias em diversos países importadores (7).

O controle de $C$. maximensis em Brachiaria spp. ainda não está definido. Acessos dessa gramínea com certo grau de resistência à doença foram encontrados (6) e híbridos, apresentando resistência à doença, também têm sido observados. No entanto, cultivares com essa característica ainda não estão disponíveis e, enquanto isso, tem sido dada ênfase ao controle químico da doença. A eficiência de fungicidas, por exemplo, aplicados na parte aérea de $B$. brizantha, foi avaliada por vários autores $(8,9,21)$. Contudo, os resultados até então obtidos não apontaram alta eficiência no controle, havendo necessidade de estudos adicionais para seleção de princípios ativos mais eficientes, definição de doses e do momento de aplicação dos produtos.

O carvão da braquiária, causado pelo fungo Ustilago operta, foi primeiramente constatado em Mato Grosso do Sul por Verzignassi et al. (20) em sementes de B. brizantha cv. BRS Piatã. Segundo os autores, possivelmente o fungo tenha sido introduzido no país por meio de sementes contaminadas. No entanto, ainda não há informações precisas sobre a sua distribuição geográfica. Conforme Marchi et al. (10), o carvão é observado também nas sementes de outras espécies e cultivares de Brachiaria spp., as quais podem ser totalmente colonizadas pelo fungo. Os sinais/sintomas são caracterizados pela presença de massas pulverulentas negras, irrompendo ou não o tegumento das sementes (20).

Diante dos riscos que a mela-das-sementes e o carvão representam direta ou indiretamente para o sistema de produção de sementes de Brachiaria spp., realizou-se este trabalho, cujo objetivo foi o de avaliar a eficiência de fungicidas no controle da mela-das-sementes e do carvão.

\section{MATERIAL E MÉTODOS}

Na safra 2012/13, realizaram-se quatro experimentos com vistas ao controle químico da mela-das-sementes e do carvão das cultivares BRS Piatã e Xaraés, de $B$. brizantha, sendo dois instalados na área

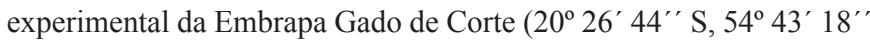
$\mathrm{O}$, altitude $541 \mathrm{~m}$ ), em Campo Grande-MS, e dois na Fazenda Fiori, em

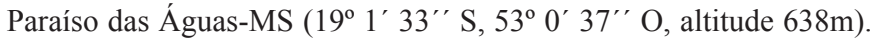
Ambos os locais apresentavam histórico de ocorrência das doenças em estudo e, ainda, o município de Paraíso das Águas constitui local de produção comercial intensiva e sucessiva de sementes de forrageiras.

Os campos das duas cultivares e nos dois locais foram implantados em solo previamente preparado, corrigido quanto à saturação em bases $(50 \%)$ e adubado, baseado em análise química. Em dezembro de 2012, realizou-se a semeadura das forrageiras a 3-5 centímetros de profundidade, em linhas espaçadas de um metro, utilizando-se o correspondente a $5 \mathrm{~kg} /$ ha de sementes puras viáveis. O delineamento experimental foi em blocos casualizados com quatro repetições e cada unidade experimental constituída por três linhas de 3 metros de comprimento, sendo a parcela útil correspondendo à área abrangida por um metro central da linha central. A partir de abril/13, quando havia cerca de $10 \%$ de antese, iniciaram-se as aplicações de fungicidas.

Para os ensaios conduzidos em Campo Grande-MS foram empregados os seguintes tratamentos (g i.a./ha): 1- testemunha (água), 2- piraclostrobina + epoxiconazole $(99,75+37,5), 3$ - trifloxistrobina + tebuconazole $(50,0+100,0)$, 4- piraclostrobina $(175,0), 5-$ carbendazim $(300,0), 6$ - azoxistrobina + ciproconazole $(80,0+32,0)$, 7- trifloxistrobina + ciproconazole $(150,0+64,0), 8$ - picoxistrobina + ciproconazole $(80,0+32,0)$, 9 - primeira aplicação: piraclostrobina $(175,0)$, segunda e terceira aplicações: piraclostrobina + epoxiconazole $(99,75+37,5), 10$ - primeira aplicação: piraclostrobina + epoxiconazole $(99,75+37,5)$, segunda aplicação: azoxistrobina + ciproconazole $(80,0+32,0)$, terceira aplicação: piraclostrobina $(175,0), 11$ - primeira aplicação: piraclostrobina + epoxiconazole $(97,5+60,0)$, segunda aplicação: tebuconazole $(120,0)$, terceira aplicação: piraclostrobina + epoxiconazole $(97,5+60,0)$.

Para os ensaios conduzidos em Paraíso das Águas-MS, os tratamentos empregados foram (g i.a./ha): 1- testemunha (água), 2piraclostrobina + epoxiconazole $(99,75+37,5), 3$ - trifloxistrobina + tebuconazole $(50,0+100,0)$, 4- piraclostrobina $(175,0), 5$ carbendazim $(300,0), 6$ - azoxistrobina + ciproconazole $(80,0+32,0)$, 7 - trifloxistrobina + ciproconazole $(150,0+64,0), 8$ - picoxistrobina + ciproconazole $(80,0+32,0), 9$ - piraclostrobina + epoxiconazole $(97,5$ $+60,0), 10$ - trifloxistrobina + protioconazol $(75,0+87,5)$.

Nos ensaios conduzidos em Campo Grande foram realizadas até três aplicações de fungicidas, com intervalo de 20 dias entre elas: primeira aplicação quando as plantas apresentavam $10 \%$ de antese, segunda aplicação aos 20 dias após a primeira aplicação, terceira aplicação aos 40 dias após primeira aplicação. Para os ensaios conduzidos em Paraíso das Águas, apenas uma aplicação foi efetuada, quando as plantas apresentavam $10 \%$ de antese. Para todos os ensaios, as aplicações foram 
efetuadas com pulverizador costal pressurizado por $\mathrm{CO}_{2}$, com pressão ajustada para $2,81 \mathrm{kgf} / \mathrm{cm}^{2}\left(40 \mathrm{psi}\right.$ ou libras $\left./ \mathrm{pol}^{2}\right)$, aferida no manômetro de saída para a barra de pulverização de $3 \mathrm{~m}$ de comprimento. As pontas de pulverização tipo leque (110-02) foram calibradas para pulverizar o volume de calda de $300 \mathrm{~L} / \mathrm{ha}$.

Realizaram-se as seguintes avaliações, efetuadas no centro de cada parcela:

a) incidência e severidade da mela-das-sementes: imediatamente antes de cada aplicação de fungicida foram amostradas 15 panículas, quantificando-se o número de panículas infectadas com mela-dassementes em relação ao total coletado e calculando-se a percentagem, correspondendo à incidência da doença. Para a severidade, avaliou-se o número de rácemos doentes contidos nas 15 panículas em relação ao total coletado e calculando-se a percentagem. Para os ensaios conduzidos em Campo Grande, essas avaliações foram efetuadas aos 20, 40 e 60 dias após aplicação (tratamentos 1 a 8) e aos 20 dias após cada aplicação para os tratamentos 9 a 11. Nos ensaios conduzidos em Paraíso das águas, as avaliações foram efetuadas aos 20 dias após aplicação dos fungicidas na cv. BRS Piatã e aos 20, 40 e 60 dias após aplicação dos tratamentos para a cv. Xaraés;

b) incidência de carvão: após a colheita das sementes, avaliaram-se 200 sementes puras. Para tanto, as sementes foram imersas em água à temperatura ambiente e, após duas horas, as mesmas foram cortadas longitudinalmente com auxílio de bisturi, quantificando-se o número de sementes com presença de massa de esporos de Ustilago operta em relação ao número total e calculou-se a percentagem;

c) colheita das sementes: ao final do experimento, procedeu-se a colheita a partir do recolhimento das sementes degranadas em tela do tipo sombrite $(50 \%)$ previamente instalado na superfície do solo dentro de cada parcela. Foi considerada apenas a linha central da parcela, incluindo-se $0,5 \mathrm{~m}$ de cada lado, perfazendo área útil $2 \mathrm{~m}^{2}$. O beneficiamento das sementes foi realizado com auxílio de peneiras e soprador de coluna, os quais removeram as impurezas e as sementes vazias. Para a cultivar BRS Piatã produzida em Paraíso das Águas, subamostras de $100 \mathrm{~g}$ de sementes foram submetidas à análise de pureza física, visando-se a determinação da produtividade de sementes puras;

d) Patologia de sementes: Para a detecção dos fungos, utilizou-se o método do papel filtro (Blotter test), sendo analisadas 200 sementes de cada parcela de cada um dos tratamentos, conforme Marchi et al. $(11,12)$. Essas sementes foram distribuídas em dez repetições, cada repetição representada por uma caixa do tipo gerbox, contendo duas folhas de papel mata-borrão esterilizado e umedecido. As sementes foram incubadas por sete dias em câmara de germinação do tipo BOD, à temperatura de $20^{\circ} \mathrm{C}$ e fotoperíodo de 12 horas e analisadas quanto ao percentual de ocorrência de fungos potencialmente patogênicos.

A partir dos valores de mela-das-sementes verificados na testemunha de ambos os experimentos, foram plotadas as curvas de progresso da doença, as quais foram confrontadas com as variáveis climáticas prevalecentes no período de avaliação da doença. Os dados climáticos foram coletados nas estações climatológicas da Embrapa Gado de Corte, em Campo Grande-MS, e de Paraíso das Águas-MS. As variáveis consideradas foram precipitação, umidade relativa e temperaturas máxima, média e mínima $\left({ }^{\circ} \mathrm{C}\right)$. Para temperatura e umidade relativa foram calculadas as médias dos sete dias que precederam à avaliação da doença, enquanto para a precipitação, obteve-se o valor acumulado durante esse período.

As análises estatísticas dos dados foram realizadas usando-se os programas Genes (3) e SAS (18).

Tabela 1. Efeito de fungicidas no controle da mela-das-sementes em Brachiaria brizantha cv. BRS Piatã, expresso pela incidência (I) e severidade (S) da doença aos 20, 40 e 60 dias após aplicação (tratamentos 1 a 8) e aos 20 dias após cada aplicação para os tratamentos 9 a 11, e na ocorrência de carvão nas sementes (\%). Campo Grande-MS, 2013.

\begin{tabular}{|c|c|c|c|c|c|c|c|}
\hline \multirow{3}{*}{$\begin{array}{l}\text { Fungicidas* } \\
\text { (g ia/ha) }\end{array}$} & \multicolumn{6}{|c|}{ Mela-das-sementes } & \multirow{3}{*}{$\begin{array}{c}\text { Sementes } \\
\text { com } \\
\text { Carvão } \\
(\%)\end{array}$} \\
\hline & \multicolumn{2}{|c|}{$1(02 / 04 / 13)$} & \multicolumn{2}{|c|}{$2(22 / 04 / 13)$} & \multicolumn{2}{|c|}{$3(16 / 05 / 13)$} & \\
\hline & I $(\%)$ & $\mathrm{S}(\%)$ & I ( $\%)$ & $\mathrm{S}(\%)$ & I ( $\%)$ & $\mathrm{S}(\%)$ & \\
\hline 1 - testemunha (água) & 0 & 0 & $57,58 a b^{* *}$ & $24,27 \mathrm{ab}$ & $68,67 \mathrm{a}$ & $33,93 \mathrm{a}$ & 0 \\
\hline 2 - piraclostrobina+epoxiconazole $(99,75+37,5)$ & 0 & 0 & $50,00 \mathrm{ab}$ & $24,88 \mathrm{ab}$ & $41,66 \mathrm{ab}$ & $7,50 \mathrm{~cd}$ & 0 \\
\hline 3 - trifloxistrobina+tebuconazole $(50,0+100,0)$ & 0 & 0 & $53,33 \mathrm{ab}$ & $30,75 \mathrm{a}$ & $23,33 \mathrm{~b}$ & $7,51 \mathrm{~cd}$ & 0 \\
\hline 4 - piraclostrobina $(175,0)$ & 0 & 0 & $66,57 \mathrm{a}$ & $31,88 \mathrm{a}$ & $28,67 \mathrm{~b}$ & $11,90 \mathrm{bcd}$ & 0 \\
\hline 5 - carbendazim $(300,0)$ & 0 & 0 & $42,07 \mathrm{abc}$ & $31,7 \mathrm{a}$ & $46,55 \mathrm{ab}$ & $17,87 \mathrm{bc}$ & 0 \\
\hline 6 - azoxistrobina+ciproconazole $(80,0+32,0)$ & 0 & 0 & $70,98 \mathrm{a}$ & $33,52 \mathrm{a}$ & $26,57 \mathrm{~b}$ & $9,57 \mathrm{bcd}$ & 0 \\
\hline 7 - trifloxistrobina+ciproconazole $(150,0+64,0)$ & 0 & 0 & $28,84 \mathrm{bc}$ & $10,74 \mathrm{bc}$ & $22,07 \mathrm{~b}$ & $9,37 \mathrm{bcd}$ & 0 \\
\hline 8 - picoxistrobina+ciproconazole $(80,0+32,0)$ & 0 & 0 & $55,49 \mathrm{ab}$ & $24,82 \mathrm{ab}$ & $24,41 \mathrm{~b}$ & $5,32 \mathrm{~d}$ & 0 \\
\hline $\begin{array}{l}9 \text { - } 1^{\mathrm{a}} \text { aplicação: piraclostrobina }(175,0), 2^{\mathrm{a}} \text { e } 3^{\mathrm{a}} \text { aplicações: } \\
\text { piraclostrobina+epoxiconazole }(99,75+37,5)\end{array}$ & 0 & 0 & $55,00 \mathrm{ab}$ & $24,73 \mathrm{ab}$ & $39,83 \mathrm{ab}$ & $11,50 \mathrm{bcd}$ & 0 \\
\hline $\begin{array}{l}10-1^{\text {a }} \text { aplicação: piraclostrobina+epoxiconazole }(99,75+37,5), 2^{\mathrm{a}} \\
\text { aplicação: azoxistrobina+ciproconazole }(80,0+32,0), 3^{\mathrm{a}} \text { aplicação: } \\
\text { piraclostrobina }(175,0)\end{array}$ & 0 & 0 & $28,82 \mathrm{bc}$ & $9,60 \mathrm{c}$ & $45,58 \mathrm{ab}$ & $19,34 \mathrm{ab}$ & 0 \\
\hline $\begin{array}{l}11-1^{\text {a }} \text { aplicação: piraclostrobina+epoxiconazole }(97,5+ \\
60,0), 2^{\text {a }} \text { aplicação: tebuconazole }(120,0), 3^{\text {a }} \text { aplicação: } \\
\text { piraclostrobina+epoxiconazole }(97,5+60,0)\end{array}$ & 0 & 0 & $15,54 \mathrm{c}$ & $3,76 \mathrm{c}$ & $24,33 \mathrm{~b}$ & $5,11 \mathrm{~d}$ & 0 \\
\hline CV (\%) & & & 47,28 & 58,30 & 62,81 & 69,89 & 0 \\
\hline
\end{tabular}

*Aplicados em até três ocasiões com intervalo de 20 dias e primeiras aplicações aos $10 \%$ de antese.

** Médias seguidas de mesma letra na coluna não diferem entre si pelo teste de Tukey a 5\% de probabilidade. 


\section{RESULTADOS E DISCUSSÃO}

Na Tabela 1 estão apresentados os resultados da intensidade da mela-das-sementes em $B$. brizantha cv. BRS Piatã, nos diferentes tratamentos avaliados em Campo Grande.

Na primeira avaliação não foi registrada a doença em qualquer dos tratamentos, uma vez que, no período anterior à avaliação, as condições climáticas foram adversas à sua ocorrência, sobretudo, temperaturas mais elevadas (Figura 1). O fato foi corroborado por Verzignassi et al. (21), que relataram que a mela-das-sementes de Brachiaria spp. manifesta-se sob condições de alta umidade e baixas temperaturas associadas a frentes frias durante o estádio de florescimento e de maturação das sementes.

A partir da segunda avaliação, houve aumento da incidência da doença em vários tratamentos, sobretudo na testemunha. No entanto, analisando-se as severidades das avaliações 2 e 3 , observou-se que os tratamentos T7 (trifloxistrobina+ ciproconazole $(150,0+64,0)$ e T11 (primeira aplicação: piraclostrobina + epoxiconazole $(97,5+$ $60,0)$, segunda aplicação: tebuconazole $(120,0)$, terceira aplicação: piraclostrobina + epoxiconazole $(97,5+60,0))$ proporcionaram os melhores resultados, mantendo a doença abaixo de $10 \%$ de severidade.
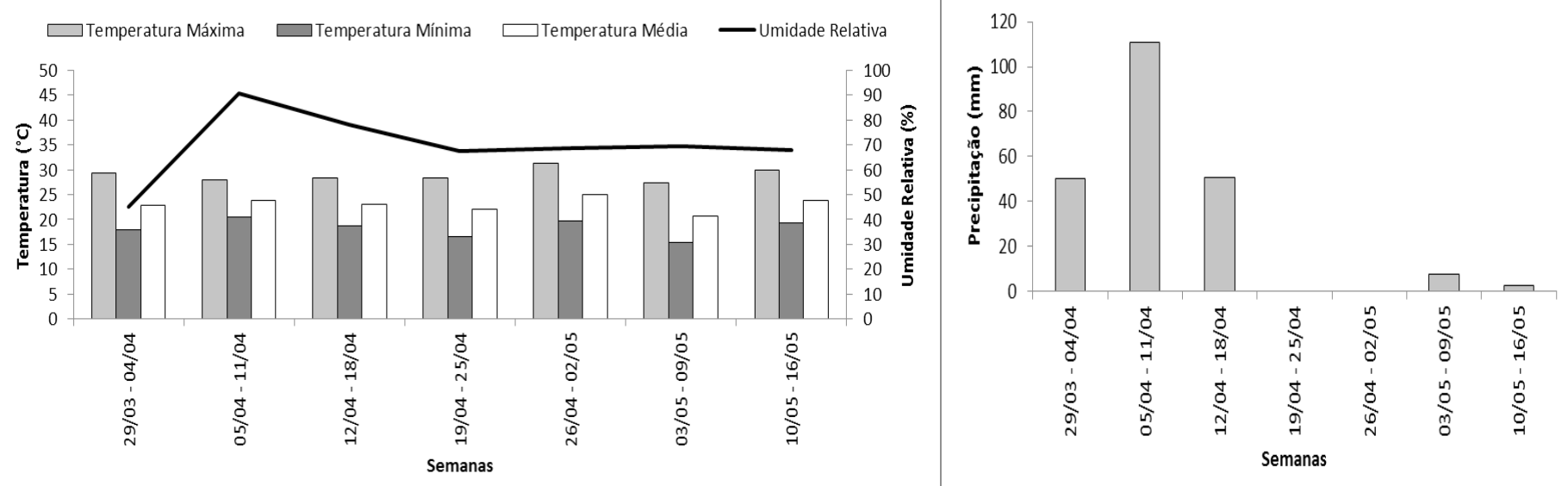

Figura 1. Temperaturas máxima, mínima e média e umidade relativa dos meses de abril e maio de 2013 e precipitação, coletadas na estação meteorológica da Embrapa Gado de Corte, em Campo Grande-MS.

Tabela 2. Efeito de fungicidas no controle da mela-das-sementes em Brachiaria brizantha cv. Xaraés, expresso pela incidência (I) e severidade (S) da doença aos 20, 40 e 60 dias após aplicação (tratamentos 1 a 8) e aos 20 dias após cada aplicação para os tratamentos 9 a 11, e na ocorrência de carvão nas sementes (\%). Campo Grande-MS, 2013.

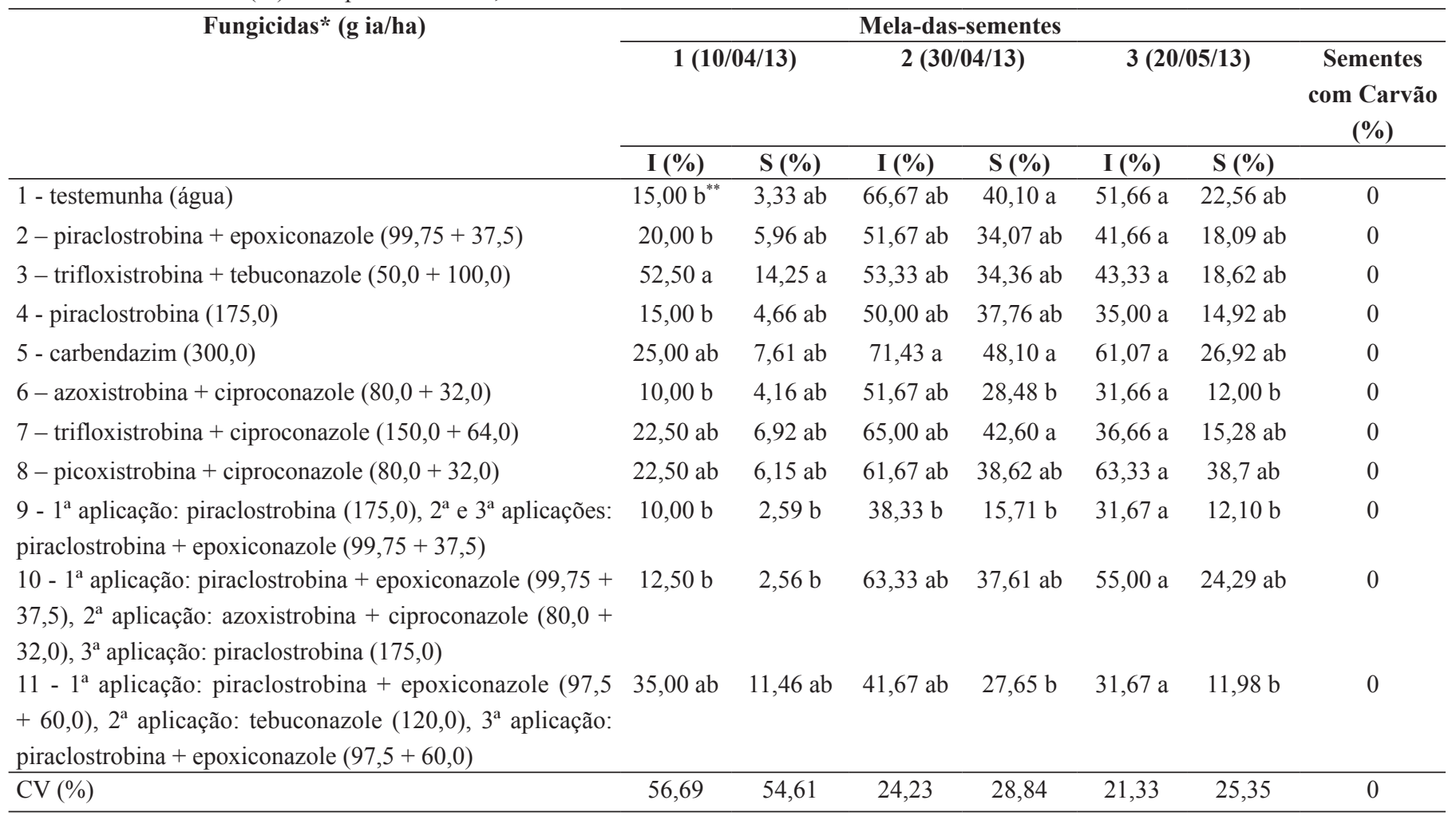

*Aplicados em até três ocasiões com intervalo de 20 dias e primeiras aplicações aos $10 \%$ de antese.

** Médias seguidas de mesma letra na coluna não diferem entre si pelo teste de Tukey a 5\% de probabilidade. 
A intensidade da mela-das-sementes em $B$. brizantha cv. Xaraés em Campo Grande encontra-se apresentada na Tabela 2.

Na primeira avaliação foi observada menor ocorrência da doença em quase todos os tratamentos. Entretanto, nas avaliações 2 e 3, quando as condições de temperatura e umidade tornaram-se mais favoráveis à mela-das-sementes (Figura 1), a incidência superou $50 \%$ em vários tratamentos. A severidade da doença foi menos expressiva nos tratamentos T6 (azoxistrobina + ciproconazole $(80,0$ $+32,0)$ ), T9 (primeira aplicação: piraclostrobina $(175,0)$, segunda e terceira aplicações: piraclostrobina + epoxiconazole $(99,75+37,5))$ e T11 (primeira aplicação: piraclostrobina + epoxiconazole $(97,5+$ 60,0), segunda aplicação: tebuconazole $(120,0)$, terceira aplicação: piraclostrobina + epoxiconazole $(97,5+60,0))$, com resultados superiores à testemunha. No tratamento T11, onde tebuconazole foi utilizado, a eficiência do referido fungicida foi consideravelmente maior. Tebuconazole foi também considerado eficiente no controle de Claviceps africana, agente causal da doença-açucarada do sorgo $(15,16)$.

Com a permanência da forrageira no campo, foi possível detectar a mela-das-sementes em $B$. brizantha cv. BRS Piatã ao longo do tempo, cujos primeiros sintomas/sinais foram observados a partir do final de abril de 2013 (Figura 2), quando houve condições favoráveis à doença (Figura 1). Segundo Verzignassi et al. (21), a mela é favorecida por alta umidade e temperatura amenas durante o estádio de florescimento e de maturação das sementes, o que implica em maior ocorrência no final do verão e início do outono (6).

Para a cultivar Xaraés, detectaram-se os primeiros sintomas/sinais de mela-das-sementes no início de abril de 2013. Constatou-se aumento

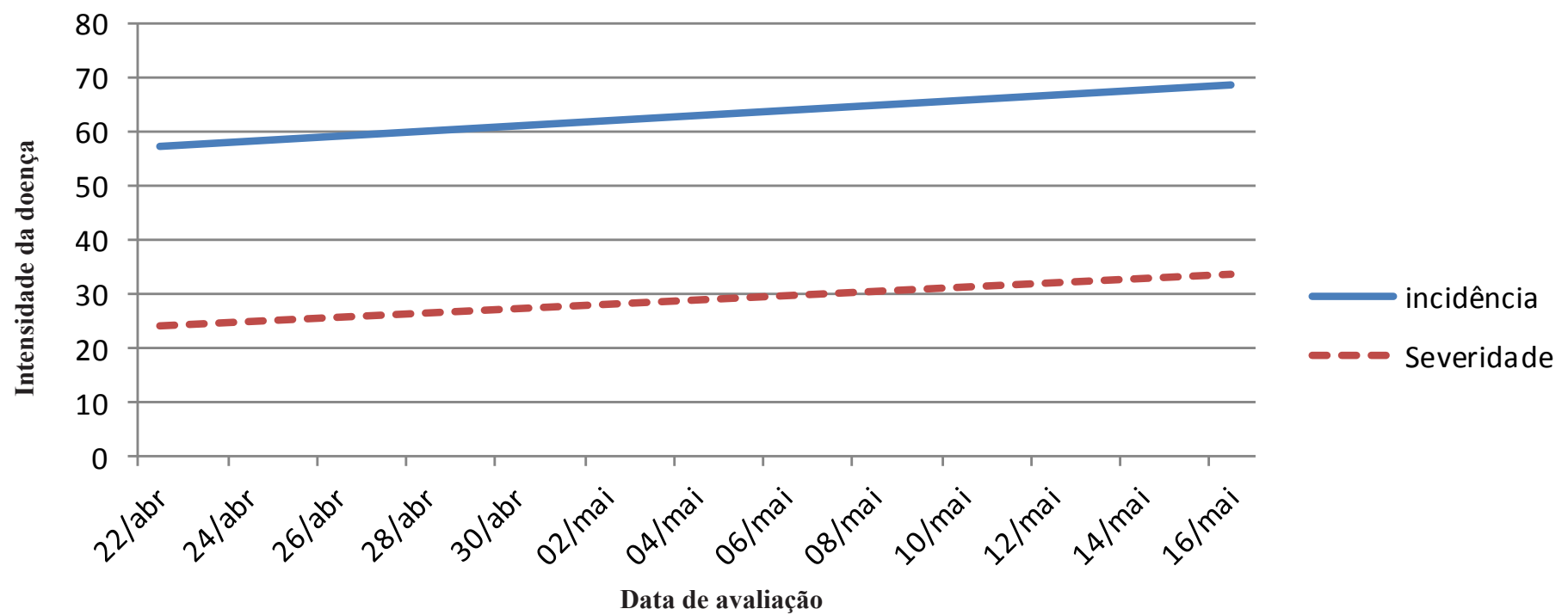

Figura 2. Progresso da intensidade de mela-das-sementes em Brachiaria brizantha cv. BRS Piatã, no período de abril a maio/2013, em Campo Grande-MS.

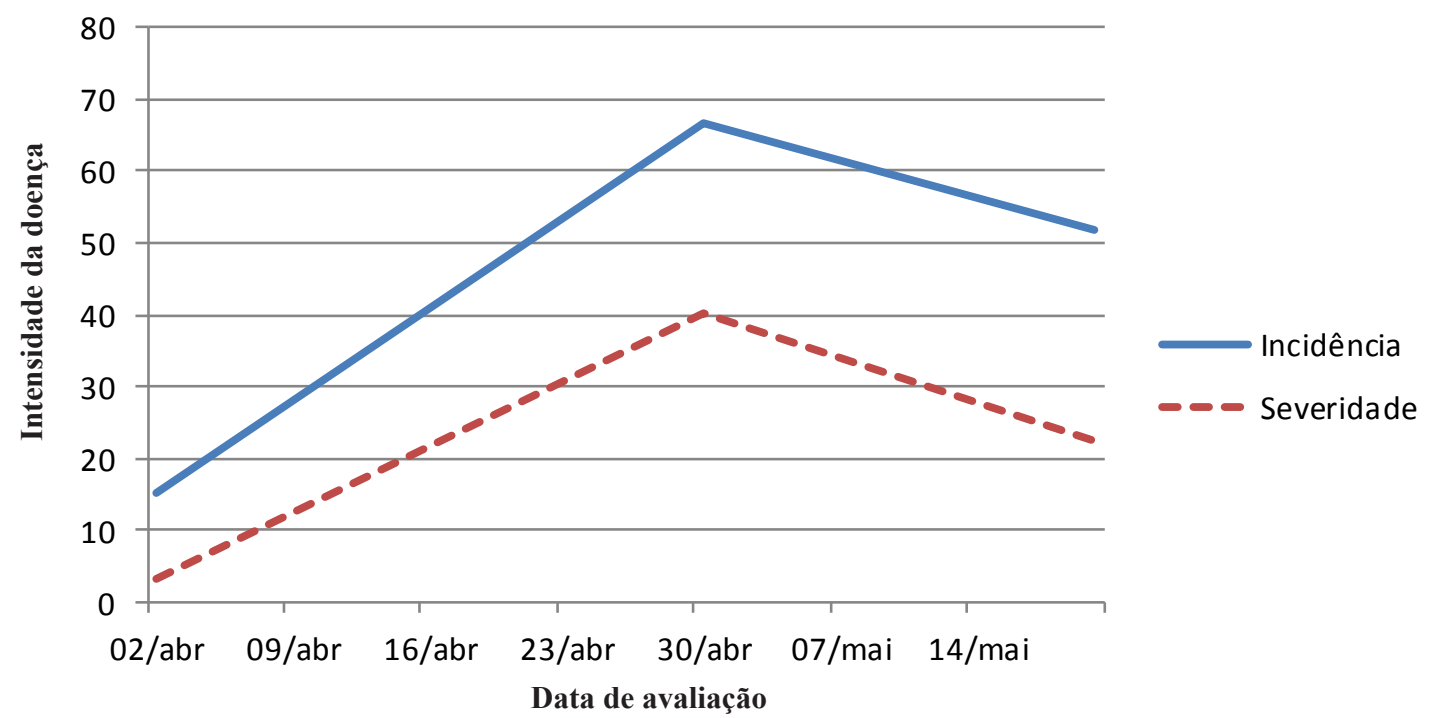

Figura 3. Progresso da intensidade de mela-das-sementes em Brachiaria brizantha cv. Xaraés, no período de abril a maio/2013, em Campo Grande-MS. 
da incidência e da severidade da doença ao longo do ensaio, atingindo-se os máximos de $66 \%$ e $41 \%$, respectivamente, no final do mesmo mês. No entanto, houve redução da intensidade de mela-das-sementes em maio de 2013 (Figura 3), devido às condições climáticas tornarem-se desfavoráveis à doença nesse período (Figura 1). Nos ensaios efetuados em Campo Grande, para ambas as cultivares, não houve ocorrência de carvão (Tabelas 1 e 2).

A disponibilidade de água parece ser fundamental para a ocorrência da doença e dispersão do patógeno (20). Observa-se também que houve influência positiva da queda da temperatura no progresso de
C. maximensis, o que é corroborado pelas observações de Verzignassi et al. (21).

Observando-se a Tabela 3, verificou-se que, em todos os tratamentos, as intensidades de mela-das-sementes e do carvão foram pouco expressivas no experimento de $B$. brizantha $\mathrm{cv}$. BRS Piatã, realizado em Paraíso das Águas-MS, dificultando a comparação entre os tratamentos estudados. Tais resultados se deveram às condições ambientais desfavoráveis às doenças, sobretudo temperaturas mais elevadas no período reprodutivo das plantas, já que tal cultivar é mais precoce (Figura 4). No entanto, houve diferenças entre os

Tabela 3. Efeito de fungicidas aplicados em Brachiaria brizantha cv. BRS Piatã no controle da melas-das-sementes, expressa pela incidência (I) e severidade (S) aos 20 dias após aplicação dos tratamentos, ocorrência de carvão nas sementes (\%) e produtividade de sementes (Kg/ha). Paraíso das Águas-MS, 2013.

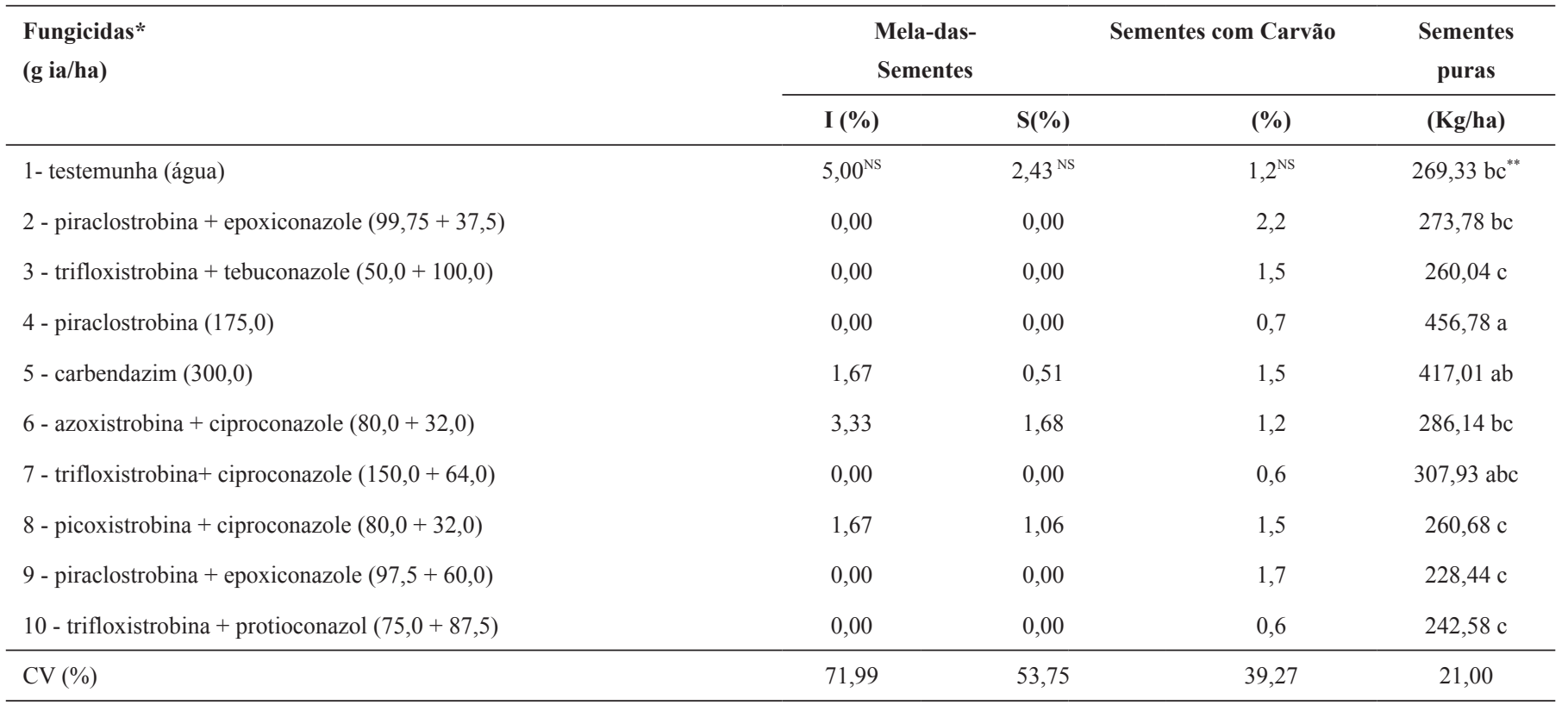

* aplicações aos $10 \%$ de antese.

** Médias seguidas de mesma letra na coluna não diferem entre si pelo teste de Tukey a 5\% de probabilidade. ${ }^{\text {NS }}$ Não significativo.
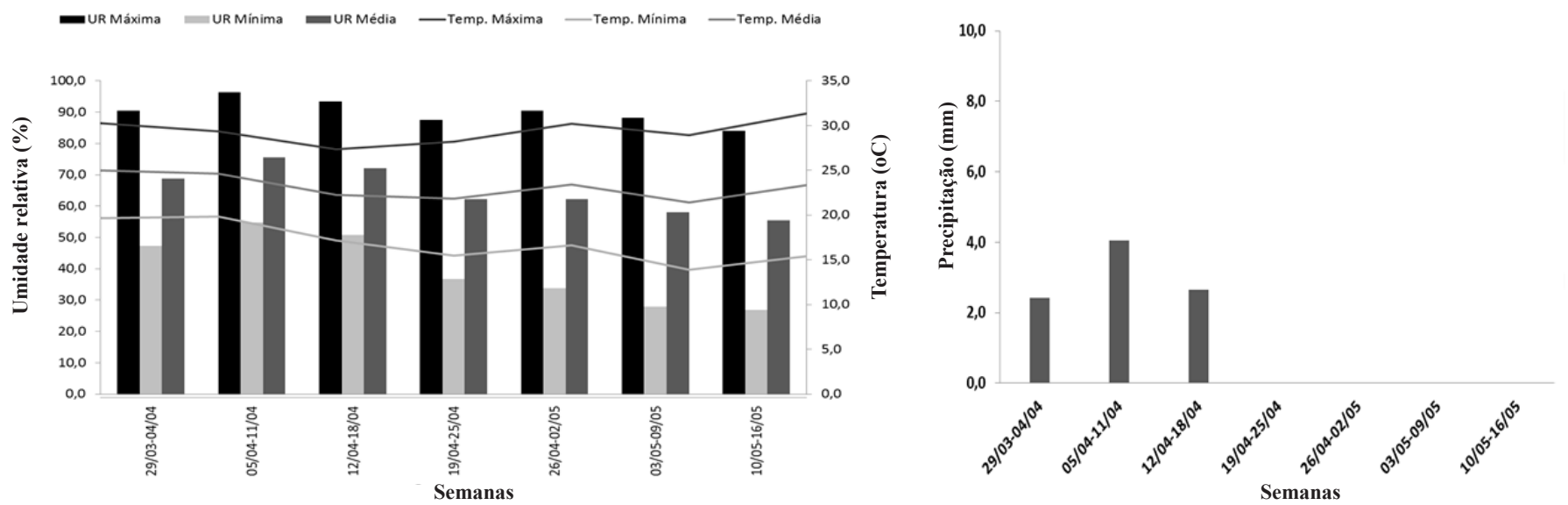

Figura 4. Temperaturas máxima, mínima e média e umidade relativa dos meses de abril e maio de 2013 e precipitação, coletadas na estação meteorológica de Paraíso das Águas-MS. 
Tabela 4. Efeito de fungicidas no controle da mela-das-sementes em Brachiaria brizantha cv. Xaraés, expresso pela Incidência (I) e severidade (S) da doença aos 20, 40 e 60 dias após aplicação dos tratamentos, e ocorrência de carvão nas sementes (\%). Paraíso das Águas-MS, 2013.

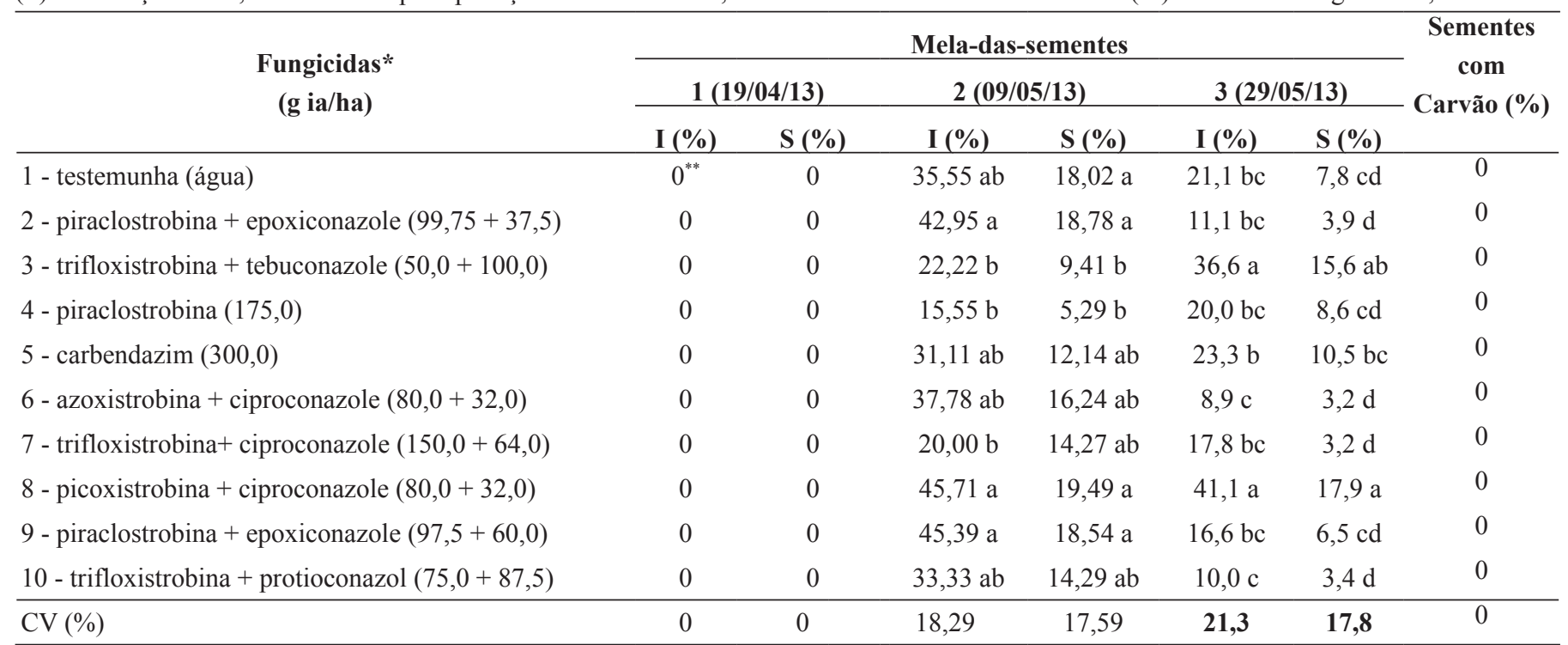

* aplicações aos $10 \%$ de antese. ** Médias seguidas de mesma letra na coluna não diferem entre si pelo teste de Tukey a 5\% de probabilidade.

Tabela 5. Efeito de fungicidas aplicados na parte aérea de Brachiaria brizantha cvs. BRS Piatã e Xaraés, expresso pela ocorrência (\%) de fungos nas sementes produzidas. Campo Grande-MS, 2013.

\begin{tabular}{|c|c|c|c|c|c|c|c|c|c|c|}
\hline \multirow{3}{*}{ Fungicidas (g ia/ha) } & \multicolumn{5}{|c|}{ Xaraés } & \multicolumn{5}{|c|}{ BRS Piatã } \\
\hline & \multicolumn{10}{|c|}{ Ocorrência (\%)* } \\
\hline & Alternaria & Bipolaris & Curvularia & Fusarium & Phoma & Alternaria & Bipolaris & Curvularia & Fusarium & Phoma \\
\hline 1 - Testemunha (água) & $5,5 \mathrm{~b} * *$ & $47,5 \mathrm{a}$ & $8,5^{\mathrm{NS}}$ & $41,5 \mathrm{ab}$ & $30,5 \mathrm{ab}$ & $1,5^{\mathrm{NS}}$ & $21,5 \mathrm{a}$ & $12,5^{\mathrm{NS}}$ & $37,5^{\mathrm{NS}}$ & $24,5^{\mathrm{NS}}$ \\
\hline $\begin{array}{l}2 \text { - piraclostrobina + epoxiconazole } \\
(99,75+37,5)\end{array}$ & $19,5 \mathrm{a}$ & $34,5 \mathrm{a}$ & 7,0 & $46,0 \mathrm{ab}$ & $28,0 \mathrm{ab}$ & 4,0 & $20,0 \mathrm{ab}$ & 5,0 & 36,0 & 22,0 \\
\hline $\begin{array}{l}3 \text { - trifloxistrobina }+ \text { tebuconazole } \\
(50,0+100,0)\end{array}$ & $13,5 \mathrm{ab}$ & $42,5 \mathrm{a}$ & 11,5 & $43,5 \mathrm{ab}$ & $46,0 \mathrm{a}$ & 1,5 & $9,5 \mathrm{~b}$ & 8,0 & 33,5 & 17,5 \\
\hline 4 - piraclostrobina $(175,0)$ & $11,5 \mathrm{ab}$ & $35,5 \mathrm{a}$ & 8,5 & $51,5 \mathrm{a}$ & $16,0 \mathrm{bc}$ & 2,0 & $15,0 \mathrm{ab}$ & 7,0 & 40,5 & 19,0 \\
\hline 5 - carbendazim $(300,0)$ & $8,5 \mathrm{ab}$ & $34,0 \mathrm{a}$ & 11,0 & $33,5 \mathrm{~b}$ & $25,0 \mathrm{~b}$ & 3,0 & $19,0 \mathrm{ab}$ & 4,0 & 37,5 & 27,5 \\
\hline $\begin{array}{l}6 \text { - azoxistrobina }+ \text { ciproconazole } \\
(80,0+32,0)\end{array}$ & $8,5 \mathrm{ab}$ & $35,5 \mathrm{a}$ & 8,5 & $47,0 \mathrm{ab}$ & $19,5 \mathrm{bc}$ & 0,0 & $13,5 \mathrm{ab}$ & 3,0 & 25,5 & 22,0 \\
\hline $\begin{array}{l}7 \text { - trifloxistrobina }+ \text { ciproconazole } \\
(150,0+64,0)\end{array}$ & $5,0 \mathrm{~b}$ & $18,0 \mathrm{~b}$ & 3,0 & $34,0 \mathrm{ab}$ & $12,5 \mathrm{c}$ & 2,5 & $11,0 \mathrm{ab}$ & 8,0 & 39,5 & 19,5 \\
\hline $\begin{array}{l}8 \text { - picoxistrobina }+ \text { ciproconazole } \\
(80,0+32,0)\end{array}$ & $10,5 \mathrm{ab}$ & $38,5 \mathrm{a}$ & 8,5 & $42,5 \mathrm{ab}$ & $26,0 \mathrm{~b}$ & 1,0 & $17,0 \mathrm{ab}$ & 5,5 & 36,0 & 23,0 \\
\hline $\begin{array}{l}9-1^{\mathrm{a}} \text { aplicação: piraclostrobina } \\
(175,0), 2^{\mathrm{a}} \text { e } 3^{\mathrm{a}} \text { aplicações: } \\
\text { piraclostrobina }+ \text { epoxiconazole } \\
(99,75+37,5)\end{array}$ & $21,5 \mathrm{a}$ & $35,0 \mathrm{a}$ & 9,0 & $38,5 \mathrm{ab}$ & $21,0 \mathrm{bc}$ & 3,5 & $15,5 \mathrm{ab}$ & 5,0 & 27,5 & 17,5 \\
\hline $\begin{array}{l}10-1^{\text {a }} \text { aplicação: piraclostrobina } \\
+ \text { epoxiconazole }(99,75+37,5)\end{array}$ & & & & & & & & & & \\
\hline $\begin{array}{l}2^{\mathrm{a}} \text { aplicação: azoxistrobina }+ \\
\text { ciproconazole }(80,0+32,0), 3^{\mathrm{a}}\end{array}$ & $16,0 \mathrm{a}$ & $31,5 \mathrm{ab}$ & 7,5 & $39,0 \mathrm{ab}$ & $23,0 \mathrm{bc}$ & 2,0 & $13,5 \mathrm{ab}$ & 4,0 & 28,5 & 19,0 \\
\hline $\begin{array}{l}\text { aplicação: piraclostrobina }(175,0) \\
11-1^{\mathrm{a}} \text { aplicação: piraclostrobina }\end{array}$ & & & & & & & & & & \\
\hline $\begin{array}{l}+ \text { epoxiconazole }(97,5+60,0), 2^{\mathrm{a}} \\
\text { aplicação: tebuconazole }(120,0), \\
3^{\mathrm{a}} \text { aplicação: piraclostrobina }+ \\
\text { epoxiconazole }(97,5+60,0)\end{array}$ & $14,0 \mathrm{ab}$ & $29,5 \mathrm{ab}$ & 7,0 & $32,0 \mathrm{~b}$ & $21,5 \mathrm{bc}$ & 0,5 & $13,5 \mathrm{ab}$ & 4,0 & 35,0 & 26,5 \\
\hline CV $(\%)$ & 46,40 & 17,77 & 59,31 & 14,53 & 22,95 & 145,12 & 34,48 & 80,71 & 19,94 & 29,82 \\
\hline
\end{tabular}

* Médias de 10 repetições, cada repetição composta por 20 sementes. Dados transformados em arcseno (x/100) $)^{1 / 2}$, médias apresentadas sem transformação. ${ }^{* *}$ Médias seguidas de mesma letra na coluna não diferem entre si pelo teste de Tukey a $5 \%$ de probabilidade. NS = não significativo 
Tabela 6. Efeito de fungicidas aplicados na parte aérea de Brachiaria brizantha cvs. BRS Piatã e Xaraés, expresso pela ocorrência (\%) de fungos nas sementes produzidas. Paraíso das Águas-MS, 2013.

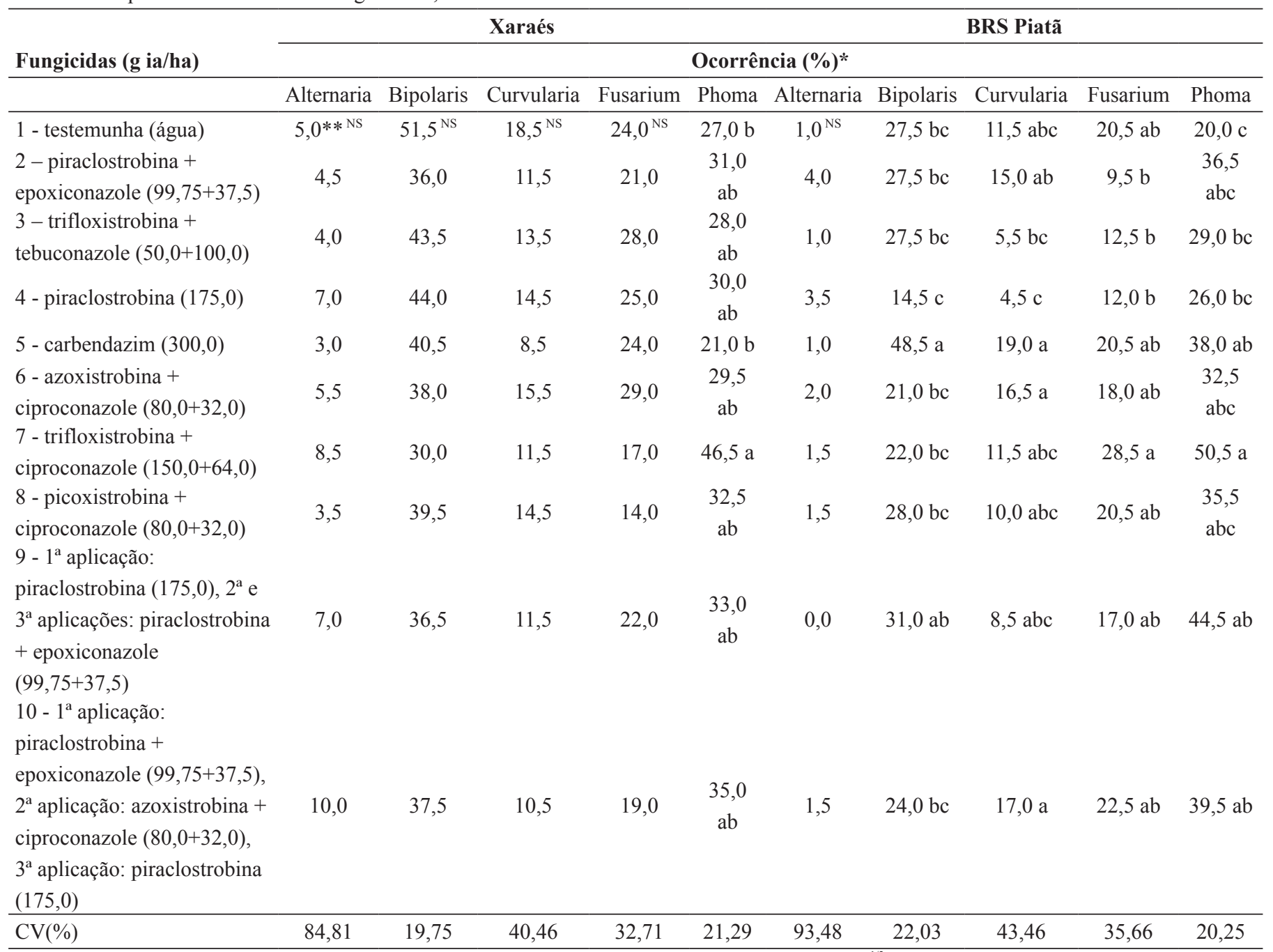

* Médias de 10 repetições, cada repetição composta por 20 sementes. Dados transformados em arcseno $(\mathrm{x} / 100)^{1 / 2}$, médias apresentadas sem transformação.

** Médias seguidas de mesma letra na coluna não diferem entre si pelo teste de Tukey a $5 \%$ de probabilidade. NS = não significativo

tratamentos para a produtividade de sementes puras. Os tratamentos T4 (piraclostrobina $(175,0))$ e T5 (carbendazim $(300,0)$ ) foram superiores à testemunha (Tabela 3 ). Assim, os produtos utilizados nos referidos tratamentos contribuíram, além do controle direto de doenças, para a melhoria da produtividade das sementes. Tal efeito já foi relatado para culturas como a soja, quando pulverizadas com estrobilurinas, como a piraclostrobina. Fagan et al. (4) observaram que plantas de soja tratadas com a referida estrobilurina tiveram o acréscimo de $7 \%$ e $8 \%$ na massa de mil grãos e de 1080 e 468 kg/ha na produtividade de grãos, quando comparado à testemunha sem aplicação e ao tratamento com triazol (tebuconazole), respectivamente. Ainda, segundo os autores, os resultados indicam que a piraclostrobina (estrobilurina) afeta a taxa de assimilação de carbono e de nitrogênio na cultura de soja, o que é refletido na produtividade de grãos. Assim, tal efeito pode ter ocorrido também com a produtividade de sementes da forrageira em estudo. Comparando-se as produtividades de sementes dos tratamentos T4 (piraclostrobina) e T1 (testemunha), 456,78 e 269,33 kg/ha, respectivamente, houve incremento médio de $69,6 \%$, possibilitando aumento da relação benefício/custo do tratamento.

No experimento com $B$. brizantha cv. Xaraés, na avaliação 1 não houve ocorrência da mela-das-sementes (Tabela 4), pois as condições ambientais não foram favoráveis à doença (Figura 2). A partir da segunda avaliação, a doença foi expressiva em alguns tratamentos. As menores severidades da doença ocorreram no tratamento T4, considerando-se as avaliações 2 e 3. Em outros tratamentos, as reduções da doença não foram consistentes, necessitando novos estudos para confirmação de resultados. Com relação ao carvão, não houve ocorrência da doença para a cultivar Xaraés em Paraíso das Águas (Tabela 4).

A análise sanitária das sementes revelou que a aplicação de fungicidas na parte aérea de plantas de Brachiaria brizantha cvs. Xaraés e BRS Piatã contribuiu para a redução da incidência dos principais fungos Alternaria spp., Bipolaris spp., Curvularia spp., Fusarium spp. e Phoma spp. (Tabelas 5 e 6). Em B. brizantha cv. Xaraés, em Campo Grande, onde houve alta incidência dos referidos fungos nas sementes, demonstrando o efeito positivo do uso de alguns fungicidas testados na redução da ocorrência de Bipolaris spp., Fusarium spp. e Phoma spp., sobretudo quando se utilizou o tratamento T7 (trifloxistrobina + ciproconazole $(150,0+64,0)$ (Tabela 5). No entanto, em Paraíso das Águas, tal efeito não ficou evidente. Para BRS Piatã, a efíciência dos fungicidas não foi expressiva, uma vez que a incidência dos fungos estudados foi baixa em todos os tratamentos, não sendo possível obter resultados conclusivos. 
- Três aplicações de fungicidas, iniciando-se com $10 \%$ de antese, 20 e 40 dias após a primeira aplicação, é boa estratégia para o controle da mela-das-sementes em cultivares de Brachiaria brizantha cvs. BRS Piatã e Xaraés, uma vez que o florescimento ocorre sequencialmente, de forma significativa, em três picos;

- Para a cultivar Xaraés, em que a mela-das-sementes é mais prejudicial, os fungicidas correspondentes aos tratamentos T4 (piraclostrobina $(175,0)$ ), T6 (azoxistrobina + ciproconazole $(80,0$ $+32,0)$ ), T9 (primeira aplicação: piraclostrobina $(175,0)$, segunda e terceira aplicações: piraclostrobina + epoxiconazole $(99,75+37,5))$ e T11 (primeira aplicação: piraclostrobina + epoxiconazole $(97,5+$ 60,0), segunda aplicação: tebuconazole $(120,0)$, terceira aplicação: piraclostrobina + epoxiconazole $(97,5+60,0))$ foram eficientes para o controle da doença;

- Na cultivar BRS Piatã, o tratamento piraclostrobina proporcionou produtividade de sementes $69,6 \%$ superior à testemunha, mesmo sem a presença expressiva das doenças estudadas, possibilitando alta relação benefício/custo do tratamento. Tal resultado função de efeitos fisiológicos proporcionados pela estrobilurina piraclostrobina, como já verificado em outras culturas;

- Quando em alta incidência de Bipolaris spp., Fusarium spp. e Phoma spp. nas sementes de Brachiaria brizantha cv. Xaraés, a aplicação de fungicidas na parte aérea das plantas, sobretudo T7 (trifloxistrobina + ciproconazole $(150,0+64,0)$, reduziu significativamente a ocorrência dos referidos fungos.

\section{REFERÊNCIAS}

1. Alves, D.B.; Barreto, R.W.; Akiba, F. Ocorrência de "ergot" causado por Claviceps sulcata em pastagens de Brachiaria decumbens no Estado do Rio de Janeiro. Fitopatologia Brasileira, Brasília, v.18, supl., p.281-281, 1993 (Resumo).

2. Chaves, Z.M.; Gomes, E.A.; Marriel, I.E.; Pfenning, L.H. Morphological and molecular characterization of Claviceps isolates from Sorghum bicolor, Brachiaria brizantha, B. decumbens and Panicum maximum in Brazil. Fitopatologia Brasileira, Fortaleza, v.29, supl., p.252-252, 2004 (Resumo).

3. Cruz, C.D. Programa Genes: Biometria. Viçosa, UFV. 382p. 2006.

4. Fagan, E.B.; Dourado Neto, D.; Vivian, R; Franco, R.B.; Yeda, M.P.P.; Massignam, L.F.; Oliveira, R.F.; Martins, K.V. Efeito da aplicação de piraclostrobina na taxa fotossintética, respiração, atividade da enzima nitrato redutase e produtividade de grãos de soja. Bragantia, Campinas, v. 69, n. $4,771-777,2010$.

5. Fernandes, C.D.; Fernandes, A.T.F.; Bezerra, J.L. Honeydew of Brachiaria seed: a new disease for Brazil. Fitopatologia Brasileira, Brasília, v.17, supl., p.218-218, 1992 (Resumo).

6. Fernandes, C.D.; Fernandes, A.T.F.; Bezerra, J.L. "Mela": uma nova doença e, sementes de Brachiaria spp. no Brasil. Fitopatologia Brasileira, Brasília, v.20, n.3, p.501-503, 1995.

7. Fernandes, C.D.; Marchi, C.E.; Jerba, V. de F.; Borges, M. de F. Patógenos associados às sementes de forrageiras tropicais e estratégias de controle. In: Zambolim, L. (Ed.). Sementes: qualidade fitossanitária. Viçosa: UFV, 2005. p.183-213.

8. Mallmann, G.; Fernandes, C.D.; Verzignassi, J.R.; Batista, M.V.; Chermouth, K.S.; Carvalho, C.; Fernandes, E.T.; Queiróz, C.A.; Silva, M.J. Efeito da aplicação de fungicidas no controle de mela-das-sementes em Brachiaria brizantha cv. Xaraés. In: VII Jornada Científica Embrapa Gado de Corte, 2011, Campo Grande. Anais. Campo Grande: Embrapa Gado de Corte, 2011.

9. Marchi, C.E.; Fernandes, C.D.; Anache, F.C.; Fabris, L.R. Progresso e controle da mela-das-sementes (Claviceps maximensis) de Brachiaria brizantha. Summa Phytopathologica, Botucatu, v.34, p.241-247, 2008.

10. Marchi, C.E.; Fernandes, C.D.; Machado, J.C.; Vechiato, M.H.; Fabris, L.R.; Sorgatto, M.; Salles, N.E.P.C.; Barbosa, C.S. Incidência de Ustilago operta em sementes comerciais de braquiária. Arquivos do Instituto Biológico, São Paulo, v.76, p.121-125, 2009.

11. Marchi, C.E.; Fernandes, C.D.; Bueno, M.L.; Batista, M.V.; Fabris, L.R. Fungos veiculados por sementes comerciais de braquiária. Arquivos do Instituto Biológico, São Paulo, v.77, p.65-73, 2010.

12. Marchi, C.E.; Fernandes, C.D.; Bueno, M.L.; Batista, M.V.; Fabris, L.R. Microflora fúngica de sementes comerciais de Panicum maximum e Stylosanthes spp. Semina - Ciências Agrárias, Londrina, v.31, p.575-584, 2010.

13. Marchi, C.E.; Fernandes, C.D.; Verzignassi, J.R. Doenças em plantas forrageiras. Campo Grande: Embrapa Gado de Corte, 2011 (Documentos, 187).

14. Pauzoutová, S.; Evolutionary strategy of Claviceps. In: White, J.F.; Bacon, C.W.; Hywel-Jones, N.L. (Ed.). Clavicipitalean fungi: evolutionary biology, chemistry, biocontroland cultural impacts. New York: Marcel Dekker, 2002. p.329-354.

15. Pinto, N.F.J. Controle químico da "ergot” (Claviceps africana Frederickson, Mantle\& de Milliano) ou doença-açucarada e das principais doenças foliares do sorgo (Sorghum bicolor (L.) Moench). Ciência e Agrotecnologia, Lavras, v.27, n.4, p.939-944, 2003.

16. Pinto, N.F.J.; Ferreira, A.S.; Casela, C.R. Ergot (Claviceps africana) ou doença-açucarada do sorgo. Circular Técnica. Embrapa-CNPMS, Sete Lagoas, n.23, 1997. 24 p.

17. Pozza, E.A.; Pomella, A.W.V.; Souza, P.E. Doenças associadas a pastagens e forrageiras na região de Lavras (MG-Brasil), de março/1992 a março/1993. Fitopatologia Brasileira, Brasília, v.19, supl., p.276-277, 1994 (Resumo).

18. SAS INSTITUTE. SAS software 9.3. Cary: Statistical Analysis System Institute, 2012. http://www.sas.com/pt_br/home.html

19. Vechiatto, M.H. Sanidade de sementes de gramíneas forrageiras. In: Simpósio Brasileiro de Patologia de Sementes, 8, 2004. João Pessoa. Anais. João Pessoa: UFPB, 2004. p.55-57.

20. Verzignassi, J.R.; Fernandes, C.D.; Doenças em forrageiras. Gado de Corte Divulga, Campo Grande, n.50, 2001.2p.

21. Verzignassi, J.R.; Souza, F.H.D.; Fernandes, C.D.; Carvalho, J.; Barbosa, M.P.F.; Barbosa, O.S.; Vida, J.B. Estratégias de controle de mela em área de produção de sementes de Brachiaria brizantha cv. Marandu. Summa Phytopathologica, Botucatu, v.29, n.1, p.66-66, 2003 (Resumo). 